\title{
Properties of polypropylene composites filled with a mixture of household waste of mate-tea and wood particles
}

\author{
Bruno D. Mattos ${ }^{\mathrm{a}}$, André L. Misso ${ }^{\mathrm{b}}$, Pedro H.G. de Cademartori ${ }^{\mathrm{c}}$, Edson A. de Lima ${ }^{\mathrm{d}}$, \\ Washington L.E. Magalhães ${ }^{\mathrm{d}}$, Darci A. Gatto ${ }^{\mathrm{a}, \mathrm{b}, *}$ \\ ${ }^{a}$ Faculty of Materials Engineering (PPGCEM), Federal University of Pelotas, Félix da Cunha 809, 96010-000 Pelotas, Brazil \\ ${ }^{\mathrm{b}}$ Forestry Engineering (PPGEF), Forest Products Laboratory, Centre for Rural Sciences, Federal University of Santa Maria, P.0. Box 221, 97105-900 Santa Maria, Brazil \\ ${ }^{\mathrm{C}}$ Wood and Forestry Science Centre (PPGEF), Federal University of Paraná, Lothário Meissner 900, 80210-170 Curitiba, Brazil \\ ${ }^{\mathrm{d}}$ Embrapa Forestry, P.O. Box 319, 83411-000 Colombo, PR, Brazil
}

\section{H I G H L I G H T S}

- Polymeric composite was developed using household and industrial residues.

- Effect of waste of mate-tea as filler was physically, chemically and mechanically evaluated.

- Thermal stability of PP decreased with addition of mate-tea waste and eucalypt particles.

- Use of eucalypt particles increased mechanical properties more than use of mate-tea waste.

- Insertion of eucalypt particles increased the hydrophobicity of the composites.

\section{A R T I C L E I N F O}

\section{Article history:}

Received 12 November 2013

Received in revised form 9 February 2014

Accepted 10 February 2014

\section{Keywords:}

Flat-pressed composites

Polymer-matrix composites

Fast-growing eucalypt

Ilex paraguariensis

\begin{abstract}
A B S T R A C T
This study presents the preparation of polypropylene composites filled with mixtures of household waste of mate-tea and eucalypt particles and aims to increase the economic value chain of mate-tea. Filler mixtures in proportions ranging from $0 \%$ to $60 \%$ with a fixed PP matrix at $40 \%$ were prepared in order to evaluate only the effect of the filler on thermochemical, physical and mechanical properties and on the morphology. The main findings showed that the addition of filler from natural sources decreased thermal stability of composites, but that the temperature of crystallisation increased. Composites with a higher proportion of wood particles showed higher hydrophobic character; however, only the composites with $60 \%$ and $54 \%$ of mate-tea waste particles showed significantly higher results for water absorption. The use of eucalypt particles increased more mechanical properties than that of household waste, which proves its efficiency as filler. Nevertheless, the use of household waste also increased the properties of the final product and showed that it can be a good alternative for the use of renewable materials in the production of polymeric composites.
\end{abstract}

(c) 2014 Elsevier Ltd. All rights reserved.

\section{Introduction}

Several lignocellulosic materials are used as fillers or reinforcement in thermoplastic composites, including fibres of sugarcane, banana, jute, ramie, flax, pineapple, curauá, sisal, cotton, coir, luffa cylindrica [1], guayule biomass [2], heart-of-peach palm sheath [3], bagasse [4], sunflower stalk flour [5], and palm leaf waste [6], as well as fibres and wood particles of different tree species [7-10].

\footnotetext{
* Corresponding author at: Faculty of Materials Engineering (PPGCEM), Federal University of Pelotas, Félix da Cunha 809, 96010-000 Pelotas, Brazil. Tel.: +55 5339211265.

E-mail address: darcigatto@pq.cnpq.br (D.A. Gatto).
}

Lignocellulosic materials have become important as fillers or reinforcements in polymer or ceramic matrices due to their advantages in relation to other inorganic or synthetic materials [3]. Some advantages of these materials are that: they are fully and easily recyclable, meeting minimum recycling content requirements; they are non-abrasive to machinery; they have the same performance for lower weight and are stronger (25-30\%) for the same weight; they result in non-brittle fracture on impact and are more shatter resistant; they have lower processing energy requirements and a low thermal expansion coefficient; they have a natural appearance, are easily coloured and are low cost, costing less than the base resin [1]. 
The low cost of the material is its most attractive factor. According to Ayrilmis and Kaymakci [11] wood flour typically costs about $0.09-0.18 € \mathrm{~kg}^{-1}$, while virgin polypropylene costs about $1.04-1.43 € \mathrm{~kg}^{-1}$. The final cost of wood polymer composites (WPCs) is significantly lower than that of solid or laminated wood decking in price, performance, and processing. This cost can be further reduced if the filler or reinforcement used is from industrial, agricultural or commercial waste.

In general, the polymeric matrix used in these materials is polypropylene (PP) in its various phases, for which $\beta$-type shows the best properties $[12,13]$. However, other matrices used include polyvinyl chloride (PVC) and high-density polyethylene (HDPE) $[2,4,14,15]$. In the last ten years, a significant increase in scientific literature about the use of such matrices for the formation of composites filled/reinforced with lignocellulosic materials has been observed [5-7,16-21]. These are used for many applications such as decks, fences, floors and automotive components [1].

The mix of a synthetic polymeric matrix with fibres/residues from natural sources influences many properties of the final product, such as physical, chemical, mechanical and anatomical properties. Nevertheless, this mix implies a decrease of wettability, hydrophobicity, thermal stability and adhesion [22,23], which should be evaluated in order to understand the behaviour of the composite when in processing or recycling. On the other hand, residues such as wood particles naturally present higher stiffness and strength than the polymeric matrix, which increases the mechanical properties of the composite [24].

In this study, household wastes of mate-tea and eucalypt particles were chosen as fillers for a PP-matrix. The filler tested is from household waste of mate-tea. Mate-tea is a non-timber product resulting from plant extractivism of Ilex paraguariensis planting trees in southern Brazil, Argentina and Uruguay, where it is used in the preparation of a popular tea drink. Per capita consumption of mate-tea in Brazil is $\sim 1.2 \mathrm{~kg} \mathrm{yr}^{-1}$, whereas in Argentina and Uruguay is $\sim 5-7 \mathrm{~kg} \mathrm{yr}^{-1}[25]$. Considering the population of the three countries, 481.000 tonnes of waste is generated annually from this consumption without any target of aggregate value, which raises the possibility of using this material in the production of thermoplastic composites.

Considering the high levels of consumption of mate-tea in these Latin American countries, any attempt to increase usage of their household waste will add value to this material. Therefore, the incorporation of household waste of mate-tea into products with higher value such as WPC becomes a strategic route to explore options for developing the industrial sector and increasing the economic value of mate. In this context, the present study aims to incorporate particles of household waste of mate-tea into flat-pressed WPCs produced with wood particles of Eucalyptus benthamii originated from a fast-growing forest population and to evaluate the thermochemical, physical and mechanical properties and the morphology of these composites.

\section{Materials and methods}

\subsection{Raw materials}

Particles of household waste of mate-tea were collected in Paraná State, Southern Brazil, and wood chips from a fast-growing eucalypt species (E. benthamii) were collected from waste of a sawing process at the Embrapa Forestry sawmill (Fig. 1). This material showed moisture content $\sim 70 \%$ on wet weight basis and was dried in an oven at $65 \pm 2{ }^{\circ} \mathrm{C}$ until constant weight was reached. Subsequently, they were cut into small particles using a Wiley knife mill (40-60 mesh).

A matrix of polypropylene - PP H103 supplied by Braskem (Brazil) with density of $0.905 \mathrm{~g} \mathrm{~cm}^{-3}$ and melt flow index of $40 \mathrm{~g} \mathrm{~min}^{-1}$ was used. The number-average molecular weight $\left(M_{n}\right)$ of the PP is 49.44 and mean weight $\left(M_{w}\right)$ is 235.597 .

\subsection{Preparation of composites}

The particles of household waste of mate-tea and eucalypt wood measuring 4060 mesh were manually mixed in distinct concentrations of particles:matrix (total weight of $80 \mathrm{~g}$ ) according Table 1.

The composites were moulded using a Marconi MA098/A electrically heated hydraulic press with homogenous distribution of pressure. The moulding process was carried out at $175 \pm 2{ }^{\circ} \mathrm{C}$ for 20 min with a pressure of $4 \mathrm{MPa}$. Direct contact between the polypropylene powder and metal platens during the heating and pressing process occurred using wax paper.

The nominal size of the composites was $140 \mathrm{~mm} \times 140 \mathrm{~mm} \times 4 \mathrm{~mm}$ after the cooling process. Moulding of the composites for the mechanical tests were performed according to ISO and ASTM standards. Additives and coupling agents were not used in the moulding process of the composites.

\subsection{Infrared spectroscopy (ATR-IR)}

ATR-IR spectra of composites A, F and L were measured in a Nicolet Nexus 570 equipment by direct transmittance at a resolution of $4 \mathrm{~cm}^{-1}$ for 32 scans in the range of $800-4000 \mathrm{~cm}^{-1}$. The alignment of the light equipment and the background spectra were collected before all the tests.

\subsection{Thermogravimetric analysis (TGA)}

Tests were done in a Shimadzu DTG-60H and composites A, F and L (4 mg per sample) were exposed to a temperature range between 20 and $600{ }^{\circ} \mathrm{C}$ at a constant heating rate of $10^{\circ} \mathrm{C} \mathrm{min}^{-1}$ under a constant inert atmosphere of $\mathrm{N}_{2}$. The weight gain (TG) and the mass loss rate (DTG) were determined.

\subsection{Differential scanning calorimetry (DSC)}

Differential scanning calorimetry (DSC) was performed in order to analyse the temperature of crystallisation $\left(T_{c}\right)$ and the melting temperature $\left(T_{m}\right)$ of composites $\mathrm{A}, \mathrm{F}$ and $\mathrm{L}$. The temperature of crystallisation was determined by heating the samples to $180^{\circ} \mathrm{C}$ and maintaining this temperature for $5 \mathrm{~min}$. The samples were then cooled to $28{ }^{\circ} \mathrm{C}$ at a rate of $5{ }^{\circ} \mathrm{C} \mathrm{min}^{-1}$. The melting temperature was determined by heating the samples to $600{ }^{\circ} \mathrm{C}$ in order to degrade them.

\subsection{Physical properties}

The density of the composites was obtained according to ASTM D792-08 and the equilibrium moisture content was calculated after stabilisation of the samples' weight under controlled environment conditions $\left(20^{\circ} \mathrm{C}\right.$ and relative humidity of $65 \%$ ). Water absorption and swelling thickness tests were carried out according to ASTM D 570-98 for 2 and $24 \mathrm{~h}$ immersions in distilled water at room temperature. Six samples of the composites were dried in an oven $\left(103 \pm 2{ }^{\circ} \mathrm{C}\right)$ at constant weight. The samples were then immersed in distilled water. At the end of the immersion period, the samples were removed from the water, the wet surface was wiped off using blotting paper, and the wet weight values were determined. Water absorption (WA\%) and swelling thickness (TS\%) were calculated using the following Eqs. (1) and (2):

$W A(\%)=\left[\left(W A_{t}-W A_{0}\right) / W A_{0}\right] * 100$

$T S(\%)=\left[\left(T S_{t}-T S_{0}\right) / T S_{0}\right] * 100$

where $W A_{0}, T S_{0}, W A_{t}$, and $T S_{t}$ denote the oven-dry weight and thickness, and weight and thickness after $t$ time, respectively.

\subsection{Wettability kinetics}

The wettability was evaluated on four samples (stabilised at equilibrium moisture content) measuring $2 \times 2 \mathrm{~cm}$ that were cut from each composite. Measurements of wettability were performed using a Dataphysics 0CA goniometer (sessile droplet method). The contact angle was determined by the placement of a deionized water droplet $(5 \mu \mathrm{l})$ on three distinct points (randomly selected) of each sample (12 measurements) and in different times, after 5, 20, 35, 50 and $65 \mathrm{~s}$.

\subsection{Mechanical properties}

The mechanical properties of the composites were evaluated through flexural strength (ISO 178), tensile strength at break (ISO 527), compressive strength (ISO 604) and adapted Janka hardness (ASTM D1037) tests for samples with small thickness. All the tests were performed in an EMIC DL30000 universal machine. 


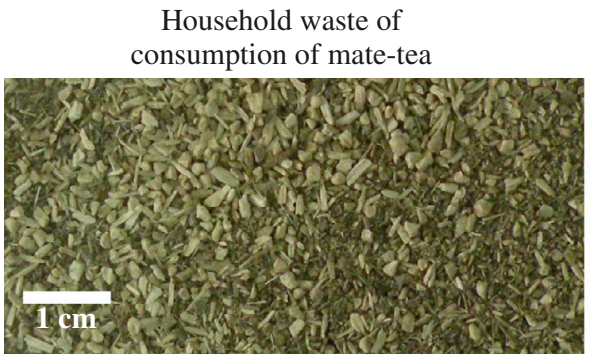

Eucalyptus wood particles

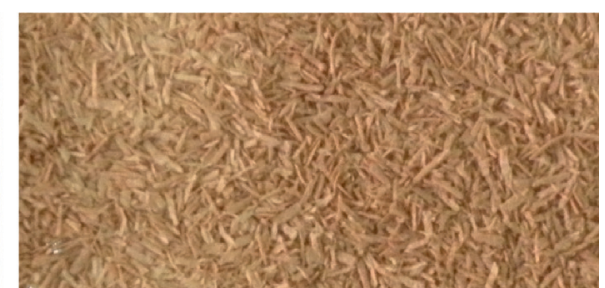

Fig. 1. Particles used in composites.

Table 1

Composition of the studied formulations.

\begin{tabular}{lrrrrrrrrrrr}
\hline Components (w/w\%) & \multicolumn{10}{c}{ Composite type } \\
\cline { 2 - 11 } & A & \multicolumn{1}{c}{ B } & C & D & E & F & G & H & I & J & \multicolumn{1}{c}{ L } \\
\hline Household waste & 60 & 54 & 48 & 42 & 36 & 30 & 24 & 18 & 12 & 6 & 0 \\
Eucalypt wood & 0 & 6 & 12 & 18 & 24 & 30 & 36 & 42 & 48 & 54 & 60 \\
PP-matrix & 40 & 40 & 40 & 40 & 40 & 40 & 40 & 40 & 40 & 40 & 40 \\
\hline
\end{tabular}

\subsection{Scanning electronic microscopy (SEM)}

Analyses of fractured surfaces of composites A, F and L obtained from flexural strength tests were performed using SEM microscopy. To achieve this, all the samples were coated with a thin gold layer with a Quick Coater Metalizer Sanyu Electron SC-701 in order to transform the composite into conductive material. The images were taken using a Shimadzu SSX 550 scanning electronic microscopic.

\subsection{Data analysis}

The distribution and variance data were evaluated. Existence of normal distribution and homogeneous variance resulted from interpretation of the data using analysis of variance (ANOVA) at 1 and $5 \%$ of probability of error. When the null hypothesis $(p<0.01$ or $p<0.05)$ was rejected, the average values were compared using Fisher LSD Test at $1 \%$ and $5 \%$ of probability of error.

\section{Results and discussion}

\subsection{Infrared spectroscopy (ATR-IR)}

As can be seen in Fig. 2, a characteristic peak of PP corresponding to $\mathrm{CH}, \mathrm{CH}_{2}$ and $\mathrm{CH}_{3}$ at $2915 \mathrm{~cm}^{-1}$ and a peak at $1471 \mathrm{~cm}^{-1}$

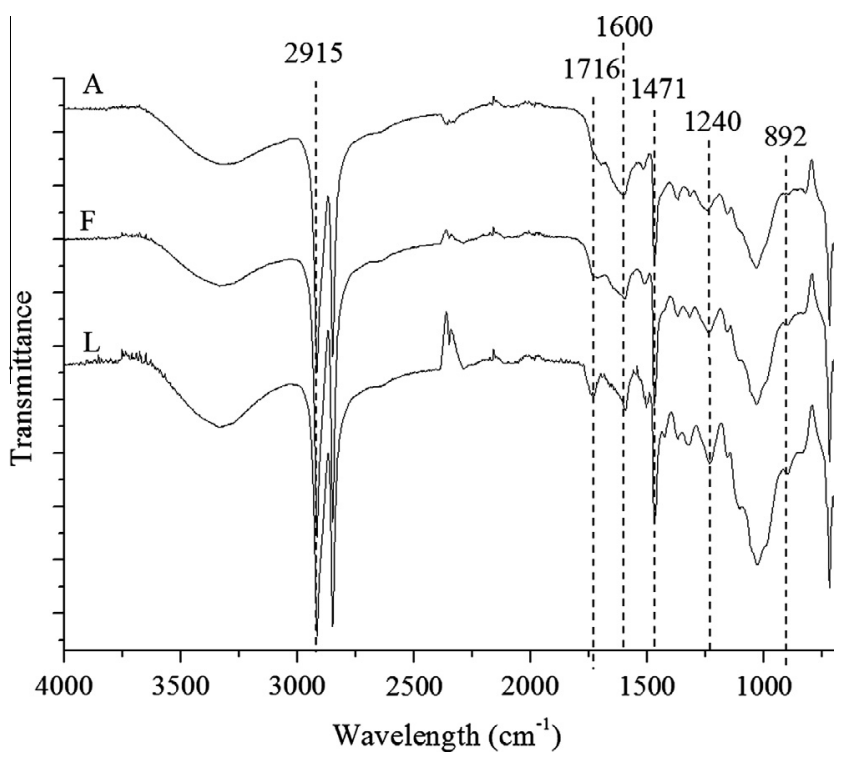

Fig. 2. ATR-IR spectra of composites A, F and L. referred to angle-deformations of $\mathrm{CH}_{3}$ are observed. Carvalho et al. [26] and Pang and Ismail [27] also verified both aforementioned peaks as a characteristic of PP. As expected, these peaks showed a similar variation of intensity because the PP content was the same for all the composites analysed.

Peaks corresponding to functional groups presented in hemicelluloses of both lignocellulosic materials (household waste and eucalypt particles) are observed at $1716 \mathrm{~cm}^{-1}(\mathrm{C}=\mathrm{O}$ stretching in xylan) and at $1240 \mathrm{~cm}^{-1}$ ( $\mathrm{C}-\mathrm{O}$ stretching vibration in xylan). The peak intensity at $892 \mathrm{~cm}^{-1}$ (C1 group frequency in cellulose and hemicelluloses) slightly increased as a function of additional eucalypt particles. The behaviour of this peak is related to the increase of polysaccharide content with increased eucalypt particles in the composites.

The increase in intensity of peaks related to hemicelluloses content results in a composite with high content of eucalypt particles that is more hydrophilic than other composites analysed in the present study. However, the presence of free $\mathrm{OH}$ groups in the materials' structure due to higher polysaccharides content is not a preponderant factor to relate with their behaviour when in contact with water.

A peak at $1600 \mathrm{~cm}^{-1}$ corresponding to a benzene ring stretching in lignin and remained constant for composites A, F and L, without high variations as a function of composite formulation. Moreover, a peak at $1471 \mathrm{~cm}^{-1}$ could be observed and is related to skeletal aromatic ring vibration in lignin [28]. Finally, the peak at $2915 \mathrm{~cm}^{-1}$ showed high intensity for all the composites and is corresponding to $\mathrm{CH}_{2}$ stretching of $\mathrm{CH}_{2}, \mathrm{CH}_{3}$ [29].

\subsection{Thermogravimetric analysis (TGA)}

The thermograms (TG) and its derivatives (DTG) in Fig. 3 showed that neat PP presented the highest onset temperature $\left(\sim 390^{\circ} \mathrm{C}\right)$ and, consequently, the highest thermal stability in relation to composites $\mathrm{A}, \mathrm{F}$ and $\mathrm{L}$.

The addition of filler to the PP matrix decreased the thermal stability of composites, which is confirmed due to the low onset temperature of all the composites in relation to the neat PP. This behaviour was also reported in the use of different matrices and fillers by Thummanukitcharoen et al. [30] and Shebani et al. [31]. The lower stability of wood at low temperatures could be attributed to high content of hemicelluloses and lignin, whereas the high stability at low temperatures is related to the higher cellulose content [32]. Nevertheless, the onset temperature of degradation depends on the period of time that the wood fibre is exposed to high temperatures [33].

Three peaks with distinct intensities according to the composition of the materials were observed. First, a peak between 0 and $100{ }^{\circ} \mathrm{C}$ indicates moisture loss of composites. The second region was characterised by a peak between 275 and $300^{\circ} \mathrm{C}$, which corresponding to the hemicelluloses degradation and presented low intensity for all the composites analysed. The third peak 

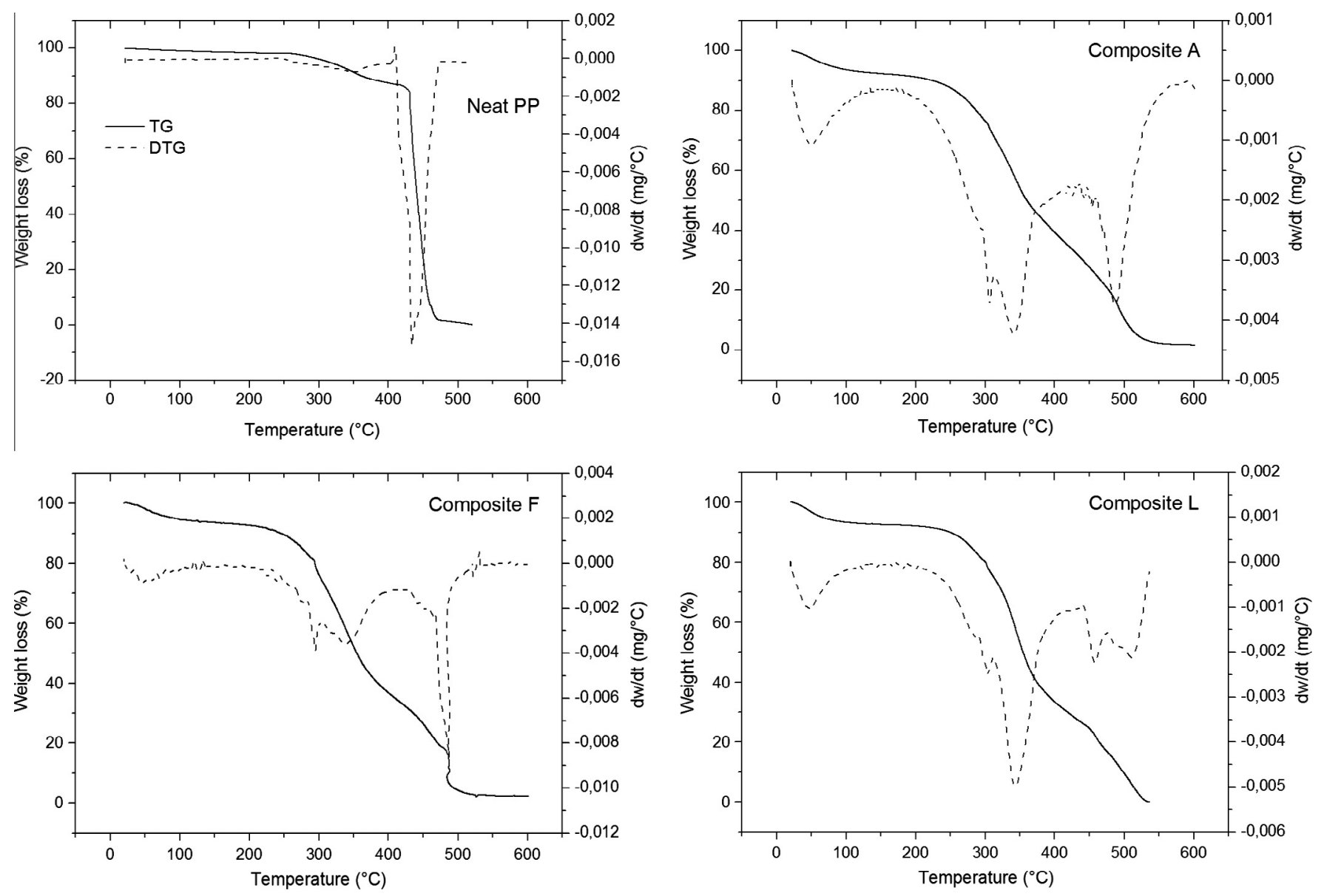

Fig. 3. Thermograms (TG) and derivative thermograms (DTG) of neat PP and composites A, F and L.

$\left(325-380^{\circ} \mathrm{C}\right)$ showed the highest intensity in the thermograms of composites $\mathrm{A}, \mathrm{F}$ and $\mathrm{L}$. This peak is related to the degradation of cellulose, one of the chemical components of wood and household waste of mate-tea.

A peak at $425-525{ }^{\circ} \mathrm{C}$ in the thermograms of the composites that corresponding to the PP degradation was observed and was confirmed through the behaviour of neat PP thermal degradation, as was also previously verified by Bai et al. [10]. In this range, lignin degradation could also occurs, which is common in the structure of wood particles and household waste of mate-tea. According to Yang et al. [34], degradation of lignin is slow and occurs from $100{ }^{\circ} \mathrm{C}$ to $900{ }^{\circ} \mathrm{C}$ with low weight loss $\left(<0.14 \mathrm{wt} . \% /{ }^{\circ} \mathrm{C}\right)$.

Composite A, which had only household waste of mate-tea and $\mathrm{PP}$, showed a residual of $1.66 \%$, whereas composite $\mathrm{F}$ presented a residual of $2.21 \%$. On the other hand, composite $\mathrm{L}$, which had only eucalypt particles and PP, showed the lowest value of residual ( $\sim 0.0015 \%)$. This behaviour could be related to a higher content of inorganic matter in the structure of household waste of matetea than those presented in eucalypt particles. Heinrichs and Malavolta [35] reported that mate-tea contains mainly K, Mg, S, Ca and $P$ as mineral elements.

\subsection{Differential scanning calorimetry (DSC)}

The crystallisation and melting patterns of composites A, F, L and neat PP-matrix obtained through DSC analysis are shown in Fig. 4. Table 2 summarises the results obtained from these curves, in which $T_{c}$ is crystallisation temperature and $T_{m}$ is melting temperature.
Crystallisation temperature of $\left(T_{c}\right)$ increased with the addition of lignocellulosic material to the PP matrix. This increase was observed as a function of additional eucalypt particles to a total of $2.21^{\circ} \mathrm{C}(1.99 \%)$, which produced a marginal effect. Borja et al. [36] and Amash and Zugenmaier [37] also reported this increment of $T_{c}$ for other lignocellulosic materials. Therefore, the addition of lignocellulosic particles acts as a nucleating agent for the crystallisation of PP. According to Sui et al. [38], dispersion of the PP matrix occurs due to the addition of particles and the promotion of heterogeneous nucleation.

Melting temperature $\left(T_{m}\right)$ did not show a tendency to increase or decrease, which was similar to results found by Ares et al. [39]. The authors observed a stabilisation of $T_{m}$ and concluded that wood flour did not affect the crystalline structure of PP, although it modified its crystallisation rate. $T_{m}$ decreased with an increase of household waste of mate-tea content and subsequently increased with an increase of eucalypt particle content. This increment shows that the mere presence of eucalypt particles in the PP matrix causes a slight increase of $T_{m}$.

As observed in Table 2, heat of crystallisation $\left(\Delta H_{f}\right)$ and crystallisation index $\left(X_{c}\right)$ decreased with addition of both particles of eucalypt and household waste of mate-tea in all composites analysed. This reduction is related to the transcrystalline region, in which restrictions in the lateral direction of growth of spherulites are observed, resulting in a columnar layer [20]. Furthermore, $X_{c}$ in composite $F$, that presents both type of particles, showed a slightly higher value than composites $\mathrm{A}$ and $\mathrm{L}$.

All the composites showed similar energy release (Fig. 5) as a function of increased temperature. This energy release occurred 

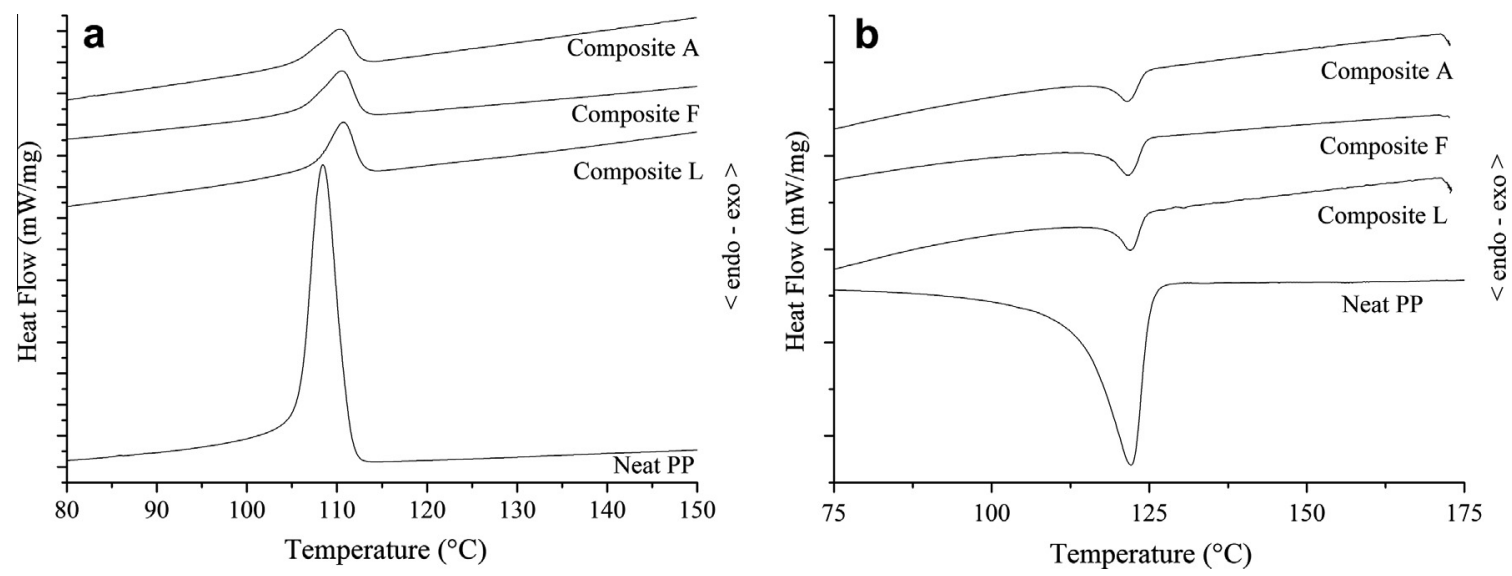

Fig. 4. Crystallisation temperature (A) and melting temperature (B) of Neat PP and composites.

Table 2

Thermal properties of Neat PP and composites A, F and L.

\begin{tabular}{lllll}
\hline & $T_{c}\left({ }^{\circ} \mathrm{C}\right)$ & $T_{m}\left({ }^{\circ} \mathrm{C}\right)$ & $\Delta H_{f}(\mathrm{~J} / \mathrm{g})$ & $X_{c}$ \\
\hline Neat PP & 108 & 122 & 76.37 & 40.19 \\
A & 110 & 121 & 11.23 & 14.77 \\
F & 110 & 121 & 13.00 & 17.10 \\
L & 110 & 122 & 11.00 & 14.47 \\
\hline
\end{tabular}

slowly and gradually to $\sim 300{ }^{\circ} \mathrm{C}$. Subsequently, an intensification at $\sim 400^{\circ} \mathrm{C}$, which is related to the initial PP degradation, was observed.

Composites A, F and L showed similar curves that are characteristic of lignocellulosic materials. Composite F showed lower peak intensities than those observed in composites A and L, probably due to the interaction between two types of residues in the same PP matrix.

\subsection{Physical properties}

Fig. 6 shows that, in general, the density of composites tends to increase with increasing proportions of eucalypt particles. The composite filled only with household waste of mate-tea (A) presents a density of $0.65 \mathrm{~g} \mathrm{~cm}^{-3}$, whereas the composite filled only with particles of eucalypt (L) showed density of $0.88 \mathrm{~g} \mathrm{~cm}^{-3}$. All the average density values found in this study were lower than the average value required by ASTM D 7032 for wood-polymer composites used to produce deck boards and guardrail systems $\left(0.97 \mathrm{~g} \mathrm{~cm}^{-3}\right)$. They were also lower than the average value indicated by Soury et al.

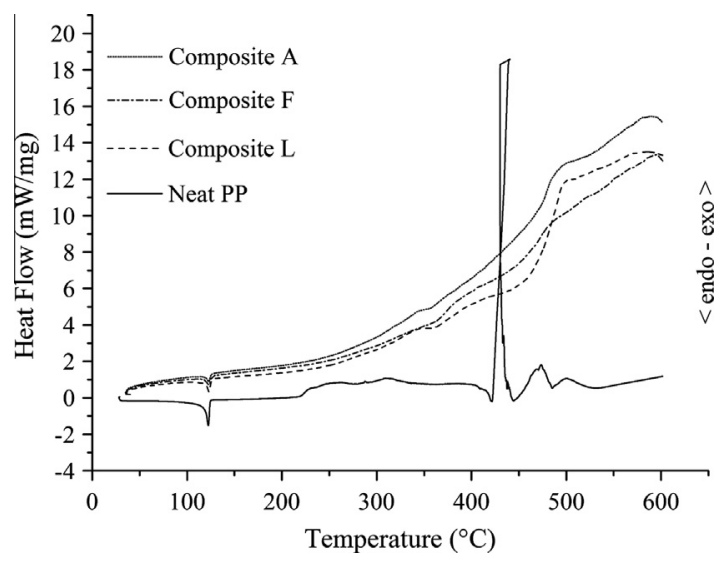

Fig. 5. DSC curves for neat PP and composites A, F and L.
[40] for utilisation in pallets $\left(1.102 \mathrm{~g} \mathrm{~cm}^{-3}\right)$. Therefore, considering only the density of composites, polypropylene composites filled with a mixture of household waste of mate-tea and wood particles could be applied in decorative products, such as skirting boards, frames and ornamental pieces.

When compared with the density of eucalypt particles $\left(0.9 \mathrm{~g} \mathrm{~cm}^{-3}\right)$, the low density of the household waste of mate-tea $\left(0.45 \mathrm{~g} \mathrm{~cm}^{-3}\right)$ was the reason for the distinct behaviour of this property. A lower density than that found in eucalypt particles is preferred for composite materials intended as wood replacement, especially in applications where light-weight components are favoured [2].

The composites with a high proportion of household waste of mate-tea showed higher equilibrium moisture than those found in composites with a high proportion of eucalypt particles. The household waste of mate-tea is a cellulosic material that suffered hydrothermal degradation during its consumption, which may have caused more hygroscopic behaviour of composites with a higher proportion of this filler. In general, natural materials used as fillers have a strong affinity with water, mainly due to the presence of $\mathrm{OH}$ groups in cellulose [21]. In these materials, low water absorption is preferred because the absorbed water causes fibre swelling and consequently low dimensional stability, decay and low long-term performance [2].

Water absorption was significantly different between the composites after both 2 and $24 \mathrm{~h}$ of immersion (Fig. 7). The highest water absorption ( $24 \mathrm{~h})$ was verified for the composites A (12.28\%) and B (10.43\%). Moreover, the rate of water absorption decreased with the inclusion of eucalypt particles, when only composite $A$ presented water absorption higher than $5 \%$ after immersion for $2 \mathrm{~h}$, differing from the others. Conversely, in the case of composite C ( $48 \%$ of mate-tea waste), regardless of the proportion of mate-tea/eucalypt, the results of the water absorption were statistically equivalent to composite L ( $60 \%$ of eucalyptus wood). I.e., for composites that have low water absorption and good utilisation of waste, composite $C$ becomes a good option.

According to Tamrakar and Lopez-Anido [41], with regards to the structural use of WPC, it is interesting that it absorbs water at a very low rate, since the moisture content directly affects the mechanical strength.

It should be emphasised that the PP matrix does not absorb any moisture [18], which indicates that all water is absorbed by the cellulosic components presented in the structure of mate-tea and wood. Thus, the hydrophilic character of these natural materials is responsible for absorbing water in this type of composite [7].

Similarly to that observed in WA\%, TS\% of composite A (only waste of mate-tea) showed the highest average value after $2 \mathrm{~h}$ of 

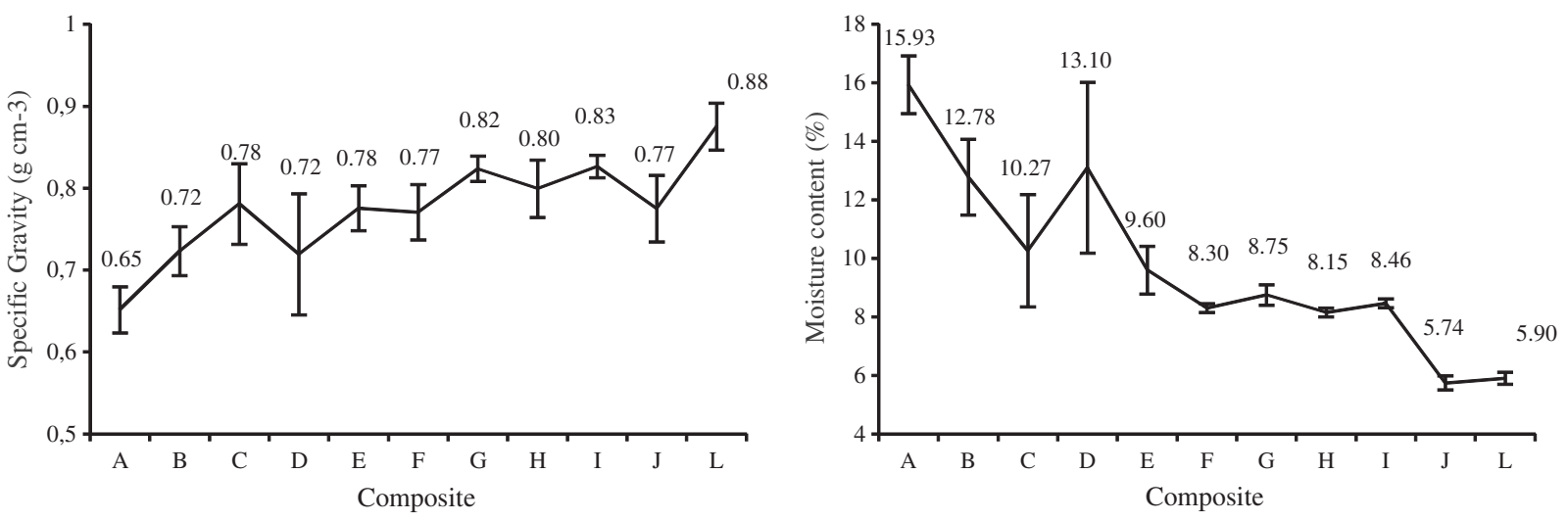

Fig. 6. Specific gravity and equilibrium moisture content.
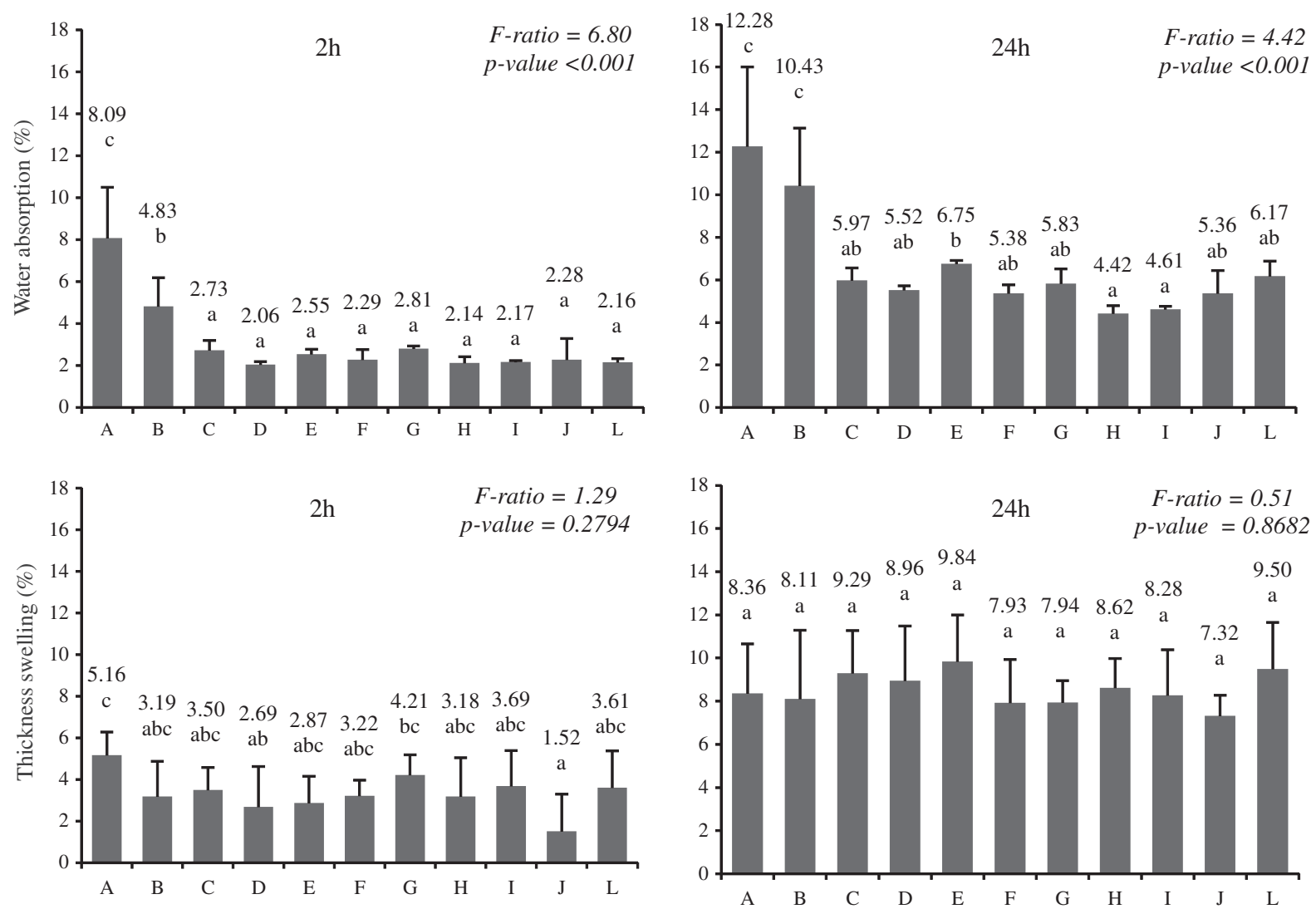

Fig. 7. Water absorption and swelling thickness of composites.

immersion, whereas composite J (54\% of eucalypt particles and 6\% of waste of mate-tea) presented the lowest value. Likewise, TS\% (24 h) of all composites showed the same behaviour, i.e., statically equal. Even with low values for TS\%, the results obtained in this study are higher than those found for previously reported polypropylene composites filled with lignocellulosic materials such as recycled newspaper fibre and poplar wood flour [42], or cotton and guayule biomass residues [2].

No chemical pre-treatments in the filler or coupling agents between matrix and filler were used. It is possible that due to the low interaction between the matrix and the filler, water can easily penetrate into the composite initially, thus increasing the percentage of thickness swelling.

As observed in Fig. 7, the maximum absorption of water (24 h) of composite A did not result in a high value for TS\%, which confirms that particles of mate-tea waste have more dimensional stability than eucalypt particles, even if they presented a more hydrophilic character. High values for swelling thickness are undesirable because they can lead to potential issues such as swelling, bowing, cupping, misalignment and loosening of fasteners when used in various building applications [2].

\subsection{Wettability kinetics}

Contact angle of composites was statistically different $(f$-ratio $=$ 106.47 and $p$-value $<0.01$ ), where composites B, C and A showed the lowest values of $\mathrm{CA}\left({ }^{\circ}\right)$ and consequently higher wettability (Table 3).

Contact angle was at a maximum at the beginning of the test ( $5 \mathrm{~s}$ ) and decreased with increased time (to $65 \mathrm{~s}$ ) for all composites, 
Table 3

Kinetics of contact angle.

\begin{tabular}{llllllll}
\hline \multirow{2}{*}{ Composite } & \multicolumn{2}{l}{ Time $(\mathrm{s})$} & \multicolumn{2}{l}{} & \multirow{2}{*}{$\Delta \mathrm{CA}\left({ }^{\circ}\right)$} \\
\cline { 2 - 6 } & 5 & 20 & 35 & 50 & 65 & Mean & \\
\hline A & 64.0 & 63.3 & 62.2 & 60.5 & 60.9 & $62.2(1.50)^{\mathrm{c}}$ & 3.1 \\
B & 58.1 & 55.8 & 53.6 & 52.8 & 50.3 & $54.1(2.97)^{\mathrm{a}}$ & 7.8 \\
C & 61.5 & 59.1 & 58.4 & 56.5 & 57.3 & $58.6(1.92)^{\mathrm{b}}$ & 4.2 \\
D & 74.6 & 73.2 & 72.4 & 71.8 & 71.3 & $72.7(1.28)^{\mathrm{e}}$ & 3.3 \\
E & 70.6 & 69.8 & 69.2 & 68.8 & 68.2 & $69.3(0.92)^{\mathrm{d}}$ & 2.4 \\
F & 69.4 & 68.7 & 68.4 & 67.8 & 67.4 & $68.4(0.77)^{\mathrm{d}}$ & 2.0 \\
G & 75.4 & 74.2 & 75.5 & 73.6 & 72.4 & $74.2(1.29)^{\mathrm{e}}$ & 3.0 \\
H & 78.3 & 76.7 & 76.3 & 75.9 & 75.5 & $76.6(1.07)^{\mathrm{f}}$ & 2.8 \\
I & 69.9 & 69.2 & 69.6 & 68.1 & 67.6 & $68.9(0.99)^{\mathrm{d}}$ & 2.3 \\
J & 74.0 & 72.8 & 72.3 & 71.7 & 71.3 & $72.4(1.06)^{\mathrm{e}}$ & 2.7 \\
L & 79.3 & 77.6 & 76.5 & 74.6 & 73.8 & $76.4(2.22)^{\mathrm{f}}$ & 5.5 \\
\hline
\end{tabular}

Values in parentheses are standard deviations.

a-f Values having the same letter are not significantly different (Fisher LSD test); $\mathrm{f}$ ratio $=106.47$ and $p$-value $<0.01$.

a finding also observed in other studies $[5,8,9,43]$ of composites filled/reinforced with other lignocellulosic materials. At the beginning of the test, a process of droplet stabilisation on the surface of the material occurs as a function of surface energy involved in the interface solid/liquid, which influences the initial contact angle. The highest droplet spread was observed in composites $B$ and L, which vary 7.8 and $5.5^{\circ}$ from first to last contact angle, respectively.

In general, natural fillers have high polarity [5] and present a contact angle lower than $90^{\circ}$, which is considered a hydrophilic surface. In this study, all composites showed contact angle lower than $80^{\circ}$ and did not present a specific behaviour related to the filler proportion (waste of mate-tea:wood). However, contact angle tended to increase with increasing eucalypt particle proportion in the composites.

In many cases, low values of contact angle are erroneously associated with a bad result; however, a low contact angle is very important for capillary flow in a complex porous structure and to achieve a strong bond between adhesive and material surfaces, for example $[9,44]$.

PP originally has low surface energy, which could be increased through additional polar materials such as lignocellulosic filler. Thus, an increase in the polarity of the composite can result in an increase of spread and in an increase of surface adhesion, observed with a reduction of the contact angle.

\subsection{Mechanical properties}

All the mechanical properties evaluated (MOE, flexural strength, tensile strength and hardness) showed a statistical difference between the composites (Table 4). In general, the behaviour of mechanical properties presented a similar tendency in relation to the average values obtained.

Modulus of elasticity (MOE) increased as a function of additional eucalypt particles. The highest average value of MOE was observed for composite L, which was $62 \%$ higher than composite $\mathrm{A}$ (household waste of mate-tea only). Therefore, composites with high content of eucalypt particles were more susceptible to an increase in strength of material rather than the occurrence of plastic deformations.

Likewise, flexural strength and tensile strength increased as a function of reduced household waste of mate-tea content. The flexural strength increased until the presence of $18 \%$ of eucalypt particles, followed by stabilisation until $48 \%$ presence of eucalypt particle content. On the other hand, tensile strength showed a constant increase until 30\% presence of eucalypt particle content followed by a sudden decrease and stabilisation until the total presence of eucalypt particles on the PP matrix.

Hardness increased as a function of additional eucalypt particles, but with lower intensity than flexural and tensile strengths. This property was statistically different only for composite A (household waste of mate-tea residues only) in relation to composites $\mathrm{I}, \mathrm{J}$ and $\mathrm{L}$, all of them with a predominance of eucalypt particles ( $48 \%, 54 \%$ and $60 \%$, respectively).

According to Magalhães et al. [3], the presence of fillers with an irregular shape does not support the stress transferred to the polymeric matrix. In this case, the incorporated material acts more as a filler than as reinforcement. Espert et al. [45] stated that the length and shape of fibres influence the mechanical properties of composites. In the present study, the shape of eucalypt particles were more homogeneous than the particles of household waste of mate-tea, which could have influenced in the relationship filler vs. reinforcement.

Furthermore, composites produced in this study satisfied the requirements of ASTM D7032 in relation to hardness ( $>6 \mathrm{MPa}$ ) and modulus of elasticity at static bending ( $>689.5 \mathrm{MPa}$ ) for utilisation in deck boards and guardrail systems. On the other hand, the minimum value of flexural strength (17.2 MPa) and tensile strength (24-27 MPa) required by ASTM D7032 for the same applications was not reached by any composites.

Nevertheless, the results of mechanical properties of composites filled with a mixture of household waste of mate-tea and wood particles verified in this study were similar to those found by $\mathrm{Li}$ et al. [46]. These authors produced LDPE composites reinforced with wood particles and bamboo charcoal and observed values of flexural strength from 14.1 to $16.9 \mathrm{MPa}$, modulus of elasticity at static bending between 1010 and $1120 \mathrm{MPa}$ and tensile strength from 10.4 to $13.4 \mathrm{MPa}$, which was enough to consider these

Table 4

Mechanical properties of composites.

\begin{tabular}{|c|c|c|c|c|}
\hline Composite & Modulus of elasticity (MPa) & Flexural Strength (MPa) & Tensile Strength (MPa) & Hardness (MPa) \\
\hline Neat PP & $1390 \pm 0.12^{*}$ & $40.7 \pm 0.7^{*}$ & $35^{* *}$ & - \\
\hline A & $919.73 \pm 83.07 \mathrm{a}$ & $7.78 \pm 0.26 \mathrm{a}$ & $4.98 \pm 1.38 \mathrm{a}$ & $23.20 \pm 1.52 \mathrm{a}$ \\
\hline B & $861.86 \pm 87.49 \mathrm{a}$ & $7.52 \pm 0.52 \mathrm{a}$ & $5.77 \pm 0.57 \mathrm{ab}$ & $24.60 \pm 2.54 \mathrm{ab}$ \\
\hline C & $1256.62 \pm 150.78 \mathrm{~b}$ & $10.38 \pm 1.01 \mathrm{~b}$ & $6.56 \pm 0.42 b c$ & $25.94 \pm 2.26 \mathrm{abc}$ \\
\hline $\mathrm{D}$ & $2568.2 \pm 205,96 \mathrm{~g}$ & $12.57 \pm 0.86 \mathrm{e}$ & $8.14 \pm 1.23 \mathrm{de}$ & $26.84 \pm 0.69$ bcde \\
\hline E & $1607.09 \pm 28.26 \mathrm{c}$ & $13.38 \pm 0.84 \mathrm{c}$ & $8.56 \pm 0.54$ ef & $25.41 \pm 0.37 \mathrm{abc}$ \\
\hline $\mathrm{F}$ & $1711.16 \pm 104.50 \mathrm{~cd}$ & $13.99 \pm 0.47 \mathrm{~cd}$ & $9.59 \pm 0.75 \mathrm{f}$ & $26.25 \pm 0.99 \mathrm{bcd}$ \\
\hline G & $1601.70 \pm 104.73 \mathrm{c}$ & $12.93 \pm 0.86 \mathrm{c}$ & $7.10 \pm 1.28 \mathrm{~cd}$ & $26.64 \pm 3.05$ bcde \\
\hline $\mathrm{H}$ & $2101.12 \pm 75.04 \mathrm{f}$ & $12.87 \pm 1.09 \mathrm{c}$ & $8.39 \pm 0.59$ ef & $27.62 \pm 1.41$ bcde \\
\hline I & $1954.37 \pm 324.15$ ef & $11.97 \pm 1.13 \mathrm{~b}$ & $7.75 \pm 0.88$ cde & $28.99 \pm 2.54$ de \\
\hline $\mathrm{J}$ & $1830.03 \pm 98.39 \mathrm{de}$ & $15.06 \pm 0.58 \mathrm{~d}$ & $8.15 \pm 0.65$ de & $28.35 \pm 1.36$ cde \\
\hline $\mathrm{L}$ & $2451.29 \pm 45.41 \mathrm{~g}$ & $13.28 \pm 0.72 \mathrm{c}$ & $8.47 \pm 0.92$ ef & $29.67 \pm 1.01 \mathrm{e}$ \\
\hline
\end{tabular}

Average values followed by different letters in the same column are statistically different at $5 \%$ of probability of error. (Fisher LSD Test, $p<0.05$ ).

* Sui et al. [38].

** Magalhães et al. [3]. 

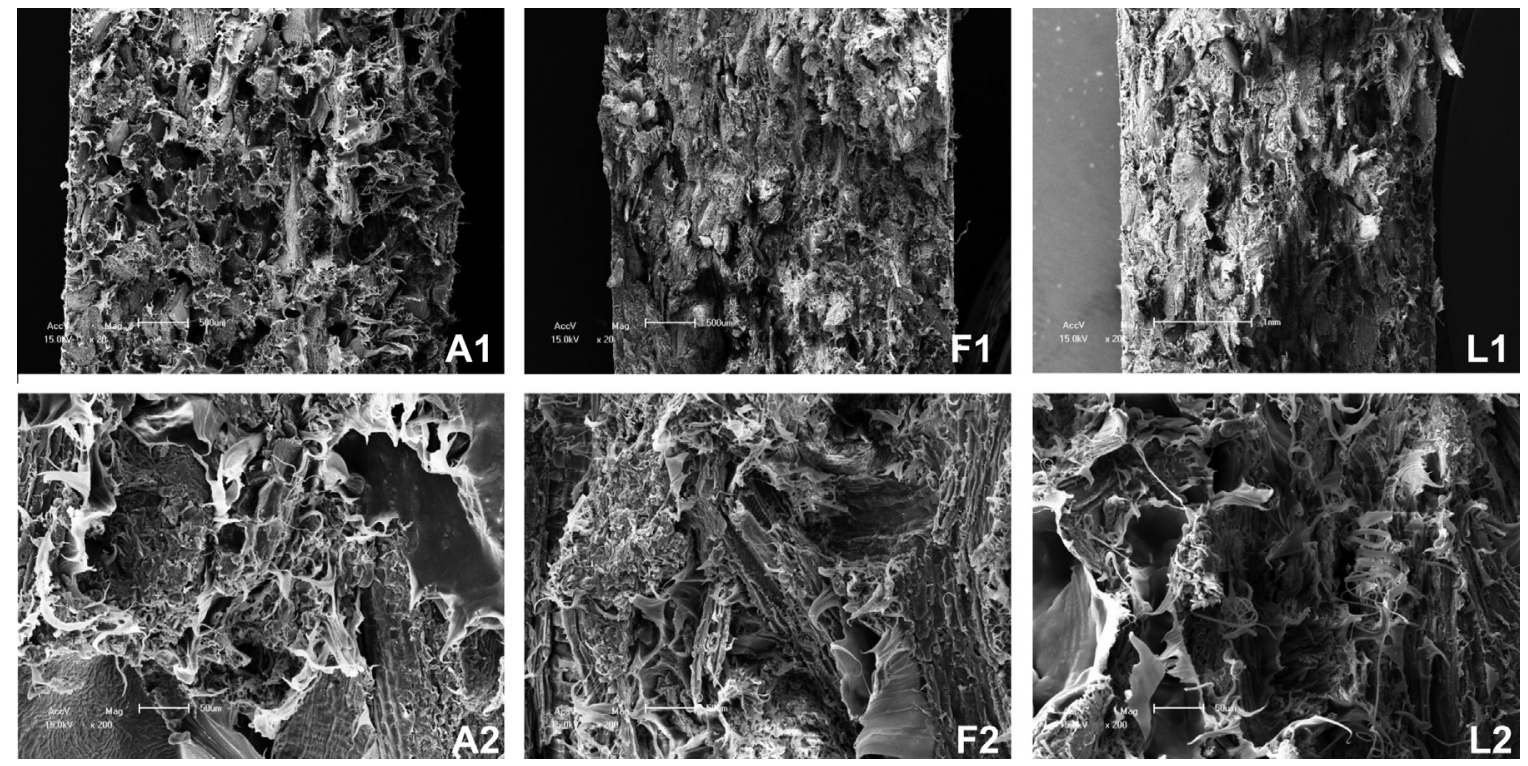

Fig. 8. Scanning electron microscopy of the fracture of composites.

composites as having good mechanical properties. Moreover, Soury et al. [40] observed modulus of elasticity at static bending of $1270 \mathrm{MPa}$ and flexural strength of $15.78 \mathrm{MPa}$ for composites used in the production of pallets, which is very similar to those found for the composites with a high proportion of wood particles produced in this study.

\subsection{Scanning electron microscopy (SEM)}

As can be observed in Fig. 8 A1 the PP matrix with only household waste of mate-tea (composite A) resulted in a higher quantity of voids than those verified in composites $\mathrm{F}$ and $\mathrm{L}$. This difference occurred mainly due to the heterogeneous shape of household waste of mate-tea. Moreover, these voids on composite A could have influenced the level of final adhesion of the material.

Continuous addition of eucalypt particles resulted in high interfacial adhesion, low surface roughness and low quantity of empty spaces. Consequently, this addition increased stiffness and mechanical strength of the material as aforementioned in the mechanical analysis.

\section{Conclusions}

Particles of household waste of mate-tea and eucalypt wood are successfully used as filler in PP to prepare composites. Thermochemical, physical, mechanical and morphological evaluations were performed.

Hemicelluloses peaks increased due to high content of this component in the chemical structure of eucalypt particles and residual mass decreased with an increase of eucalypt particle content on the PP matrix. Temperature of crystallisation significantly increased with the addition of any lignocellulosic material.

The composite with higher proportion of eucalypt particles was more hydrophobic. These composites tend to show more interesting properties referring to contact angle, but if the purpose is a composite with high adhesion and spreading, the use of mate-tea waste becomes interesting.

Mechanical properties significantly increased with the addition of eucalypt particles in relation to household waste content, except for hardness, which increased with low intensity.

\section{Acknowledgments}

The authors wish to thank CNPq (National Counsel of Technological and Scientific Development) and CAPES (Coordination for the Improvement of Higher Education Personnel) for supporting this work.

\section{References}

[1] Satyanarayana KG, Arizaga GGC, Wypych F. Biodegradable composites based on lignocellulosic fibers - an overview. Prog Polym Sci 2009;34:982-1021.

[2] Bajwa SG, Bajwa DS, Holt G, Coffelt T, Nakayama F. Properties of thermoplastic composites with cotton and guayule biomass residues as fiber fillers. Ind Crops Prod 2011:33:747-55.

[3] Magalhães WLE, Pianaro SA, Granado CJF, Satyanarayana KG. Preparation and characterization of polypropylene/heart-of-peach palm sheath composite. J Appl Polym Sci 2013;2013(127):1285-94.

[4] Darabi P, Gril J, Thevenon MF, Karimi AN, Azadfalah M. Evaluation of high density polyethylene composite filled with bagasse after accelerated weathering followed by biodegradation. BioRes 2012;2012(7):5258-67.

[5] Kaymakci A, Ayrilmis N, Gulec T. Surface properties and hardness of polypropylene composites filled with sunflower stalk flour. BioRes 2013;2013(8):592-602.

[6] Binhussaina MA, El-Tonsy MM. Palm leave and plastic waste wood composite for out-door structures. Constr Build Mater 2013;47:1431-5.

[7] Ashori A, Nourbakhsh A. Reinforced polypropylene composites: effects of chemical compositions and particle size. Bioresour Technol 2010;11:2515-9.

[8] Ayrilmis N. Effect of fire retardants on surface roughness and wettability of wood plastic compoistes panels. BioRes 2011;6:3178-87.

[9] Jarusombuti S, Ayrilmis N. Surface characteristics and overlaying properties of flat-pressed wood plastic composites. Eur J Wood Prod 2011;69:375-82.

[10] Bai G, Guo C, Li L. Synergistic effect of intumescent flame retardant and expandable graphite on mechanical and flame-retardant properties of wood flour-polypropylene composites. Constr Build Mater 2014;50:148-53.

[11] Ayrilmis N, Kaymakci A. Fast growing biomass as reinforcing filler in thermoplastic composites: Paulownia elongata wood. Ind Crops Prod 2013;43:457-64.

[12] Cao Y, Feng J, Wu P. Simultaneously improving the toughness, flexural modulus and thermal performance of isotactic polypropylene by $\alpha-\beta$ crystalline transition and inorganic whisker reinforcement. Polym Eng Sci 2010;50:222-31.

[13] Prachum Y, Adam Strauss RH, Kiatkamjornwong S. The physical and mechanical properties of beta-nucleated polypropylene/montmorillonite nanocomposites. J Appl Polym Sci 2011;122:1066-76.

[14] Jeamtrakull S, Kositchaiyong A, Markpin T, Rosarpitak V, Sombatsompop N. Effects of wood constituents and content, and glass fiber reinforcement on wear behavior of wood/PVC composites. Compos Part B Eng 2012;43:2721-9.

[15] Fang Y, Wang Q, Guo C, Song Y, Cooper PA. Effect of zinc borate and wood flour on thermal degradation and fire retardancy of Polyvinyl chloride (PVC) composites. J Anal Appl Pyrolysis 2013;100:230-6. 
[16] Joseph PV, Mathew G, Joseph K, Thomas S, Pradeep P. Mechanical properties of short sisal fiber-reinforced polypropylene composites: comparison of experimental data with theoretical predictions. J Appl Polym Sci 2003;88:602-11.

[17] Hadal RS, Dasari A, Rohrmann J, Misra RDK. Effect of wollastonite and talc on the micromechanisms of tensile deformation in polypropylene composites. Mater Sci Eng A Struct Mater 2004;372:296-315.

[18] Bledzki AK, Letman M, Viksne A, Rence L. A comparison of compounding processes and wood type for wood fibre-PP composites. Compos Part A Appl Sci Manuf 2005;36:789-97.

[19] Tajvidi M, Najafi SK, Moteei N. Long-term water uptake behavior of natural fiber/polypropylene composites. J Appl Polym Sci 2006;99:2199-203.

[20] Somnuk U, Eder G, Phinyocheep P, Suppakarn N, Sutapun W, Ruksakulpiwat Y. Quiescent crystallization of natural fibers-polypropylene composites. J Appl Polym Sci 2007;106:2997-3006.

[21] Haque MM, Hasan M, Islam MS, Ali ME. Physico-mechanical properties of chemically treated palm and coir fiber reinforced polypropylene composites. Bioresour Technol 2009;100:4903-6.

[22] Nuñez AJ, Kenny JM, Reboredo MM, Aranguren MI, Marcovich NE. Thermal and dynamic mechanical characterization of polypropylene-woodflour composites. Pol Eng Sci 2002;42:733-42.

[23] Hristov V, Vasileva S. Dynamic mechanical and thermal properties of modified poly(propylene) wood fiber composites. Macromol Mater Eng 2003;288:798-806.

[24] Mengeloğlu F, Karakuş K. Some properties of eucalyptus wood flour filled recycled high density polyethylene polymer-composites. Turk J Agric For 2008;32:537-46.

[25] Pagliosa CM, de Simas KN, Amboni RDMC, Murakami ANN, Petkowicz CLO, Medeiros JDD, et al. Characterization of the bark from residues from mate tree harvesting (Ilex paraguariensis St. Hil.). Ind Crops Prod 2010;32:428-33.

[26] Carvalho GMXd, Mansur HS, Vasconcelos WL, Oréfice RL. Obtenção de compósitos de resíduos de ardósia e polipropileno. Polim 2007;17:98-103.

[27] Pang AL, Ismail H. Tensile properties, water uptake, and thermal properties of polypropylene/waste pulverized tire/kenaf (PP/WPT/KNF) composites. BioRes 2013;8:806-17.

[28] Baldock JA, Smernik RJ. Chemical composition and bioavailability of thermally altered Pinus resinosa (Red pine) wood. Org Geochem 2002;33:1093-109.

[29] Laurent M, Matuana LM, Jin S, Stark NM. Ultraviolet weathering of HDPE/ wood-flour composites coextruded with a clear HDPE cap layer. Pol Degrad Stab 2011;96:97-106.

[30] Thummanukitcharoen P, Limpanart S, Srikulkit K. Preparation of Organosilane Treated Microcrystalline (SiMCC) and SiMCC/Polypropylene Composites. J Met Mater Miner 2012;22:13-9.
[31] Shebani AN, van Reenen AJ, Meincken M. The effect of wood extractives on the thermal stability of different wood species. Thermochim Acta 2008:471:43-50.

[32] Tserki V, Matzinos P, Kokkou S, Panayiotou C. Novel biodegradable composites based on treated lignocellulosic waste flour as filler. Part I. Surface chemical modification and characterization of waste flour. Compos Part A Appl Sci Manuf 2005;36:965-74.

[33] McHenry E, Stachurski ZH. Composite materials based on wood and nylon fibre. Compos Part A Appl Sci Manuf 2003;34:171-81.

[34] Yang H, Yan R, Chen H, Lee DH, Zheng C. Characteristics of hemicellulose, cellulose and lignin pyrolysis. Fuel 2007;86:1781-8.

[35] Heinrichs R, Malavolta E. Composição mineral do produto comercial da ervamate (Ilex paraguariensis St. Hil.). Cienc Rural 2001;31:781-5.

[36] Borja Y, Rieß G, Lederer K. Synthesis and characterization of polypropylene reinforced with cellulose I and II fibers. J Appl Polym Sci 2006;101:364-9.

[37] Amash A, Zugenmaier P. Morphology and properties of isotropic and oriented samples of cellulose fibre-polypropylene composites. Polymer 2000;41:1589-96.

[38] Sui WZ, Fuqua M, Ulven C. Properties of polypropylene composites fabricated using twin-screw extrusion. In: Proceedings of the 16th international conference on composite materials, Kyoto Japan; July 2007.

[39] Ares A, Bouza R, Pardo SG, Abad MJ, Barral L. Rheological, mechanical and thermal behaviour of wood polymer composites based on recycled polypropylene. J Polym Environ 2010;18:318-25.

[40] Soury E, Behravesh AH, Rouhani EE, Zolfaghari A. Design, optimization and manufacturing of wood-plastic composite pallet. Mater Des 2009;30:4183-91.

41] Tamrakar S, Lopez-Anido RA. Water absorption of wood polypropylene composite sheet piles and its influence on mechanical properties. Constr Build Mater 2011;25:3977-88.

42] Ashori A, Sheshmani S. Hybrid composites made from recycled materials: moisture absorption and thickness swelling behavior. Bioresour Technol 2010;101:4717-20.

[43] Lu JZ, Wu Q. Surface characterization of chemically modified wood: dynamic wettability. Wood Fiber Sci 2006;38:497-511.

[44] Aydin I. The effects of some manufacturing conditions on wettability and bonding os veneers obtained from various wood species. Trasbzon, Turkey: Dissertation, Black Sea Technical University; 2004.

[45] Espert A, Vilaplana F, Karlsson S. Comparison of water absorption in natura cellulosic fibres from wood and one-year crops in polypropylene composites and its influence on their mechanical properties. Compos Part A Appl Sci Manuf 2004:35:1267-76.

[46] Xiang L, Bingrong L, Zhidan L, Langhuan H, Shaozao T, Xiang C. The utilization of bamboo charcoal enhances wood plastic composites with excellen mechanical and thermal properties. Mater Des 2014;53:419-24. 